\title{
Ser dividido: concepções modernas na poesia de Sophia de Mello Breyner Andresen
}

\section{Split self: modern conceptions in the poetry of Sophia de Mello Breyner Andresen}

Samla Borges Canilha

Pontifícia Universidade Católica do Rio Grande do Sul (UFRGS), Porto Alegre, Rio Grande do Sul / Brasil

samlaaborges@gmail.com

Resumo: Entre os grandes poetas que os portugueses legaram ao mundo, está Sophia de Mello Breyner Andresen. Com uma obra notável, tanto pela extensão quanto pela qualidade, a poeta destaca-se como um objeto ainda a se tratar na academia, de forma que o tempo apenas serve à sua consagração. É buscando reforçar o refinamento característico de sua obra que, neste artigo, demonstro como, a partir da leitura de Coral, a poesia de Andresen pode ser pensada a partir da concepção de lírica moderna proposta por Hugo Friedrich. Para tanto, a leitura do texto literário foi realizada considerando-se a discussão sobre os conceitos de lírica e de lírica moderna, em específico, atentado-se a textos além do de Friedrich. Disso, pude observar como a poesia de Andresen serve de expressão da divisão provocada no homem pelo mundo moderno. Essa divisão, porém, pode ser salva pela transfiguração, através da linguagem, da realidade em poesia.

Palavras-chave: Sophia de Mello Breyner Andresen; lírica moderna; modernidade.

Abstract: Among the great poets that the Portuguese introduced to the world is Sophia de Mello Breyner Andersen. With a notable work, in both extension and quality, the poet stand out as an object yet to be 
treated by the academia, as the time seems to increase the validation of her work. It's in the path of the characteristic refinement of her work that this article seeks to demonstrate, from the reading of Coral, that Andersen's poetry can be studied in the light of Hugo Friedrich concepts of modern lyric. For this task, the reading of the literary text was done taking into consideration the discussion of lyric, in general, and modern lyric, in particular, paying close attention to the works beyond Friedrich. This reading lead to the conclusion that Andersen's poetry works as a mean of expression of the division that the modern world induces in the human being. This division, however, can be saved by transfiguration, through language, of the reality into poetry.

Keywords: Sophia de Mello Breyner Andresen; modern lyric; modernity.

Data de submissão: 23 de agosto de 2018

Data de aprovação: 8 de janeiro de 2019

Se há algo que Portugal lega ao mundo, são grandes poetas. Além dos nomes óbvios, como o clássico Camões ou o genial Fernando Pessoa, há aqueles que, tão próximos temporalmente de nós, têm, ainda, sua obra sendo e a ser minuciosamente explorada pela crítica. Para alguns, o tempo acaba por trazer o esgotamento; para outros, porém, o tempo serve apenas para consagrar a riqueza de suas obras. Este é o caso de Sophia de Mello Breyner Andresen.

Sophia - como é intimamente chamada, diversas vezes, pelos críticos -, que atravessou o século XX (1919-2004), teve a consagração de sua poesia ainda em vida, recebendo diversos prêmios. Entre eles, vários são destacáveis: o Grande Prémio de Poesia da Sociedade Portuguesa de Escritores, por Livro sexto, em 1964; o Prémio da Crítica, do Centro Português da Associação Internacional de Críticos Literários, pelo conjunto da sua obra, em 1983; o Prémio P.E.N. Clube Português de Poesia, por Ilhas, em 1990; o grande Prémio Camões, em 1999, tendo sido a primeira mulher portuguesa a recebê-lo; e, no final da vida, em 2003, o Prémio Rainha Sophia de Poesia Ibero-americana.

Foi instigada pela aclamação de sua obra que optei por abordar sua poesia neste trabalho. Entre uma obra tão extensa e rica, a escolha por um 
corpus de análise é sempre complexa; porém, de forma completamente arbitrária, optei por Coral como sustentação da proposta que aqui me coloco a resolver: demonstrar como a poesia de Andresen pode ser pensada a partir do paradigma de lírica moderna proposto pelo alemão Hugo Friedrich. Apesar de trabalhar com apenas um dos seus títulos, amparo-me na afirmação de Eucanaã Ferraz (2018, p. 18) sobre a poesia de Andresen de que "do primeiro ao último livro, ouvimos a mesma voz, e por isso mesmo identificamos sem esforço suas modulações" para realizar afirmações de caráter genérico em relação a sua obra, procurando fazer as devidas observações quando necessário o for.

Por partir de um conceito de caráter claramente formalista, a análise a que me proponho concentra-se nos poemas como construções fechadas em si, sem pensar seu vínculo com a vida da poeta ou com o contexto português - apesar de este ser um elemento de forte presença na poesia de Andresen, marcada pelo engajamento político em alguns momentos. Cabe, apenas, pensá-los em relação à modernidade de forma ampla, sempre me baseando nas ideias de Friedrich. ${ }^{1}$ Antes, porém, de entrar nesta e na obra da poeta em específico, cabe abordar o conceito de lírica de forma mais geral.

Anatol Rosenfeld, em $O$ teatro épico, dedica-se a, antes de tratar sobre o épico em específico, abordar os diferentes gêneros literários e o que chama de seus "traços estilísticos", isto é, os traços que caracterizam cada um dos gêneros como tais. Sua classificação, de raiz clássica, distingue três: épico, lírico e dramático. Estes, porém, como bem ressalta o autor, não podem ser pensados isoladamente, pois, em seus termos, "não existe pureza de gêneros em sentido absoluto" (ROSENFELD, 1985 , p. 16), uma vez que os gêneros partilham traços. ${ }^{2}$

Não me dedicarei, aqui, a retomar as ideias do autor sobre a épica e o drama, concentrando-me na lírica. Esta se caracteriza, para o crítico, pela tradução de um estado de alma através de um discurso marcado pelo ritmo e pela musicalidade das palavras e dos versos. Essa ritmicidade é que o aproxima da música - elemento a ser destacado por

\footnotetext{
${ }^{1}$ Como toda e qualquer proposta teórica, a de Friedrich apresenta falhas. Entretanto, não me dedicarei a elas, por ora.

${ }^{2}$ Além de reforçar essa ideia, colocando-a como explicação para a multiplicidade de tipos já realizados historicamente, Staiger (1975) destaca a arbitrariedade de tal denominação.
} 
diversos outros autores que pensam o assunto. Rosenfeld (1985) destaca também a subjetividade, colocando a lírica como gênero da expressão de emoções e disposições psíquicas - remetendo à concepção romântica do gênero -, e caracterizando-a pela presentificação, isto é, pelo relato de uma experiência presente e, portanto, breve - mas, por isso, de maior intensidade expressiva.

Tanto a tripartição dos gêneros quanto diversas das características mencionadas estão presentes também na proposta de Emil Staiger. O autor vincula o gênero lírico à recordação: "O passado como tema do lírico é um tesouro da recordação" (STAIGER, 1975, p. 55). O valor dos versos, na lírica, estaria na unidade entre a significação das palavras e sua música, o que faz com que cada sílaba seja insubstituível e imprescindível (STAIGER, 1975). A partir do som e do ritmo, é recriada no leitor a disposição anímica (Stimmung) do poeta - o estar-um-no-outro -, reação não necessariamente lógica ou conceitual. Tal efeito, que remete às disposições psíquicas de que Rosenfeld já havia tratado, porém, só resulta da mencionada união entre som e significado e é alcançado, novamente, pelo uso de verbos no presente, que provocam uma extensão do sentimento expresso a qualquer outro momento em que ocorra o contato com o texto, em uma espécie de "momento eterno".

$O$ gênero é, em síntese, para o autor:

Unidade entre a música das palavras e de sua significação; atuação imediata do lírico sem necessidade de compreensão; perigo de derramar-se, retido pelo refrão e repetição de outro tipo; renúncia à coerência gramatical, lógica e formal; poesia da solidão compartilhada apenas pelos poucos que se encontram na mesma “disposição anímica” (STAIGER, 1975, p. 51).

Nessa concepção, consta também a separação entre sujeito lírico e sujeito de criação, elementos que, na poesia romântica, estavam vinculados. A desvinculação apontada por Staiger é uma das transformações que ocorrem nas discussões sobre a lírica a partir da modernidade. $\mathrm{O}$ vínculo, então, se dá entre sujeito lírico e criação, e não mais criador. Assim, apesar de uma perspectiva, em certos aspectos, romântica - como ao considerar que o poeta lírico abandona-se à inspiração, a uma ação involuntária -, Staiger, ao considerar também a união entre som e significado, aponta para uma perspectiva moderna, pois tal pode ser percebida principalmente a partir de poetas do século 
XX, como Baudelaire, Rimbaud e Mallarmé, aos quais Hugo Friedrich irá se dedicar em seu Estrutura da lírica moderna.

Em tal obra, Friedrich procura evidenciar uma estrutura que percebe entre os três autores mencionados e que pode ser pensada em relação à lírica moderna ocidental de forma geral - apesar de seu recorte restringir-se aos franceses. A leitura que o autor realiza é de teor formalista, estrutural, pois procura os paradigmas para seu conceito em questões formais das obras dos poetas em questão.

A lírica europeia do século XX seria, em sua perspectiva, obscura, de difícil acesso, característica esta que é proposital:

A poesia quer ser [...] uma criação auto-suficiente, pluriforme na significação, consistindo em um entrelaçamento de tensões de forças absolutas, as quais agem sugestivamente em estratos pré-racionais, mas também deslocam em vibrações as zonas de mistério dos conceitos (FRIEDRICH, 1978, p. 16).

Essa autossuficiência é marcada por tensões formais e temáticas que resultam do fato de o sujeito poético ser, agora, uma "inteligência que poetiza", um “operador da língua" (FRIEDRICH, 1978, p. 17). Evitase, portanto, uma intimidade comunicativa, que dá lugar a um trabalho formal atento, visto, em alguns momentos, como quase matemático. Esse rigor acaba resultando em inovadores poemas, muitas vezes, carregados de uma dramaticidade agressiva, produtores de um efeito de choque. A concepção formalista de Friedrich em relação ao discurso literário pode ser entrevista também no argumento de que tais textos carregam certa anormalidade, provocam estranheza. Essa sensação resulta do trabalho com a língua, que está, aqui, separada do conteúdo. A poesia passa a girar, então, em torno de si própria, afirma o crítico ao tratar da obra de Baudelaire:

O desconcertante de tal modernidade [de Baudelaire] é que está atormentada até à neurose pelo impulso de fugir do real, mas se sente impotente para crer ou criar uma transcendência de conteúdo definido, dotada de sentido. Isto conduz os poetas da modernidade a uma dinâmica de tensão sem solução e a um mistério até para si mesmos. Baudelaire fala muitas vezes do sobrenatural e do mistério. Só se compreende o que ele quer dizer com isto quando - como ele próprio fez - se renuncia a dar a estas palavras outro conteúdo que não seja o próprio mistério absoluto. 
A idealidade vazia, o "outro" indefinido que, no caso Rimbaud é mais indefinido ainda e no de Mallarmé se converterá no Nada, e o mistério que gira em torno de si mesmo, próprio da lírica moderna, são correspondentes (FRIEDRICH, 1978, p. 49).

O termo "modernidade", segundo Friedrich, foi criado em 1859 pelo poeta francês, primeiro ao qual se dedica. A obra do francês tem como problema em específico a possibilidade da poesia na civilização do comércio e dominada pela técnica. Para entender tal afirmação, cabe apresentar a contextualização dada por Álvaro Cardoso Gomes em $A$ estética simbolista.

Entre os antecedentes históricos e culturais, o autor destaca a Revolução Industrial e, com ela, a "obsessão da velocidade e da competição" (GOMES, 1985, p. 9). Atrelado a esse desenvolvimento industrial está o científico, que promoveu tentativas de explicação racional do Universo - do que é exemplar o Positivismo de Comte. É notável, portanto, o desprezo pela metafísica. Atrelado a esse avanço tecnológico está o apagamento do sujeito, tornando-se ele também apenas mais uma parte das engrenagens das máquinas das linhas de montagem. Com isso, o homem vê-se abandonado em um mundo que não consegue acessar, levando-os à descrença e ao desalento. Além disso, a velocidade com que as mudanças se dão gera uma sensação de que tudo se esgota no tempo. ${ }^{3}$

O mal estar provocado por tal contexto acabou gerando duas tendências: uma existencial, o Decadentismo, e uma literária, o Simbolismo, cujos principais nomes são, para Gomes (1985), justamente Baudelaire, Rimbaud e Mallarmé. Tais autores se destacam pelo rigor técnico e pela disciplina, apresentando novos temas e uma subjetividade que controlava as emoções. As principais características do movimento a que eles pertencem, segundo o autor, são a capacidade sugestiva, a musicalidade da expressão e o idealismo de origem platônica (traços, deve-se salientar, que já estavam presentes antecipadamente em alguns românticos e parnasianos). Esses elementos também serão abordados por Friedrich ao abordar a escrita de tais poetas.

Para o crítico alemão, é na modernidade que inicia a despersonalização da lírica moderna, pois o que é produzido já não

\footnotetext{
${ }^{3}$ Pode-se pensar, assim, que uma poesia mais estrutural que temática é uma tentativa de manter-se no tempo, de ser acessível, compreendida, mesmo que o conteúdo se perca.
} 
pode ser relacionado com os fatos biográficos dos autores produtores ele exemplifica isso ao comentar que os poemas de Baudelaire não eram datados; logo, não têm como serem associados a eventos de sua vida. $\mathrm{O}$ poema, então, reforça Friedrich, não mais comunica, apenas é. Com isso, dá-se espaço para o sonho e para a fantasia, tornando-se característica dessa produção a abstração, no sentido de intelectualidade, de ação não natural. Passam a serem características da poesia:

Beleza dissonante, afastamento do coração do objeto da poesia, estados de consciência anormais, idealidade vazia, desconcretização, sentido de mistério, gerados nas forças mágicas da linguagem e da fantasia absoluta, aproximados às abstrações da matemática e às curvas melódicas da música (FRIEDRICH, 1978, p. 58).

Os esboços teóricos de Baudelaire têm, segundo Friedrich, realização em Rimbaud. Este se destaca, entre outros aspectos, pela defesa da poesia moderna acompanhada de reflexão sobre a arte poética e pela desumanização intensificada - o sujeito lírico pode, agora, vestir diversas máscaras, impedindo ainda mais a correção com o poeta criador.

Esse impedimento torna-se extremo na poesia de Mallarmé, que leva ao ápice uma estrutura poética que se foi definindo a partir de Baudelaire. Entre as recorrências, Friedrich aponta:

ausência de uma lírica do sentimento e da inspiração; fantasia guiada pelo intelecto; aniquilamento da realidade e das ordens normais, tanto lógicas como afetivas; manejo das forças impulsivas da língua; sugestionabilidade em vez de compreensibilidade; consciência de pertencer a uma época tardia da cultura; relação dupla para com a modernidade; ruptura com a tradição humanística e cristã; isolamento que tem consciência de ser distinção; nivelamento do ato de poetar com a reflexão sobre a composição poética (FRIEDRICH, 1978, p. 95).

A preocupação, então, passa a ser a formação de uma realidade, e não uma reprodução. Essa realidade fundada é de pura potência da linguagem, e a vida natural, nesse contexto, é afastada, interessando apenas, tematicamente, aquilo que é artificial, criado - como os objetos industriais ou, quando se trata das flores, aquelas que são cultivadas, não as que brotam naturalmente da terra. Essa artificialidade extrema 
dá margem ao silêncio como traço presente, estando este vinculado a uma linguagem concisa e suave quanto à musicalidade. Para alcançar tal resultado, o poeta dedica-se a um alto rigor formal que evidencia, cada vez mais, a linguagem como exteriorização de si mesma, e não mais como comunicação, de forma a se "prescindir de matérias da experiência cotidiana, de conteúdos didáticos ou outros utilitários, de verdades práticas, de sentimentos corriqueiros, da embriaguez do coração" (FRIEDRICH, 1978, p. 135-136), afinal, "[...] a poesia é uma construção de per si” (FRIEDRICH, 1978, p. 138).

Alfonso Berardinelli, em Da poesia à prosa, porém, critica a escolha e o posicionamento adotados por Friedrich. O teórico italiano vê na teoria do alemão uma limitação, pois a poesia aparece desvinculada do contexto histórico - o que é recriminável:

a lírica de que nos fala Friedrich em seu livro basta a si mesma. Não necessita mais do mundo, evita qualquer vínculo com a realidade. Nega-lhe até a existência. Fecha-se numa dimensão absolutamente autônoma. Fantasia ditatorial, transcendência vazia, puro movimento da linguagem, ausência de fins comunicativos, fuga da realidade empírica, fundação de um espaço-tempo sem relações causais e dissociado da psicologia e da história: a lírica que, segundo Friedrich, entrou em cena no Ocidente a partir da segunda metade do século XIX é sobretudo isso. Poesia despersonalizada e alheia à história, ela deve ser lida e analisada como um organismo cultural e estilístico auto-suficiente. Após os três extensos capítulos dedicados a Baudelaire, Rimbaud e Mallarmé (capítulos em que os dados biográficos e históricos são quase de todo ausentes), seria possível dizer que essa poesia se apresenta em seu conjunto como um criação sem sujeito, uma obra sem autores. Como um sonho ou um labirinto dentro do qual os autores aprenderam a morar e de onde não poderiam sair (BERARDINELLI, 2007, p. 21).

Mallarmé, o grande exemplo de Friedrich, porém, é um caso extremo. O sujeito - mesmo que não o poeta, mas o sujeito lírico -, afinal, tem forma como elemento poético no Simbolismo. Afinal, o que ocorre é, segundo Gomes (1985), o rompimento com o modo explícito e direto de se dizer as coisas. Portanto, o sujeito ainda é importante como aquele em quem reverbera o objeto desses poemas, que lhe serve como estímulo. A poesia pela poesia surge como uma forma de desautomatizar essa 
relação, por isso, o simbolista, segundo o autor, procura a essência das coisas - esforço que se dá, entre outros recursos, pelo uso da sinestesia, que serve como esforço para recuperar a linguagem original, instintiva, sem a intervenção da inteligência. $O$ simbolista (e esta é talvez a ideia que mais me interessa aqui, como se poderá ver) procura a união entre o material e o espiritual na experiência terrestre, de forma a "recuperar a unidade de um mundo artificialmente dividido" (FEIDELSON, 1969, p. 56 apud GOMES, 1985, p. 16).

Tal união é que tomo como chave de leitura para a obra poética de Sophia de Mello Breyner Andresen neste trabalho, apesar de a poeta distar quase um século dos simbolistas - afinal, as gerações não deixam de se influenciar. Para Rosenfeld (1985, p. 23), na poesia moderna, “o mundo, a natureza, os deuses, são apenas evocados e nomeados para, com maior força, exprimir a tristeza, a solidão ou a alegria da alma que canta", de forma que o universo poeticamente retratado é expressão de uma interioridade, extensão do sujeito. Na escrita da portuguesa, a relação entre os elementos funciona de forma semelhante. O crítico Eduardo Lourenço, inclusive, aponta para essa relação:

Identificada como uma sílfide com a vida silenciosa e as metamorfoses dos elementos mais fluidos do universo, a poesia da Sophia ainda quase adolescente pôde parecer irreal, etéria, aristocrática, vaga tardia de um simbolismo tão fundo que nem de símbolos precisava, espécie de vôo sem matéria através de experiências, evocações, presságios, de tão musical ressonância que bem audacioso seria quem descobrisse nela, para lá de rilkeanos acertos ao imponderável sentimento de si perante o universo e seu perfil indeciso, a amorosa das coisas e dos gestos que o nome justo e a visão clara subtraem à perpétua evanescência para que fiquem na nossa memória como anjos em perpétua e fulgurante vigília (LOURENÇO, 1975, p. II).

Antes, porém, cabe apresentar algumas características que podem ser identificadas em seus poemas. Em relação ao uso da linguagem, Andresen realiza uma poesia de sintaxe clara e direta. Apesar de soar de tom elevado, o vocabulário utilizado é bastante simples; a complexidade está, talvez, na força das imagens com ele construídas. O poeta brasileiro Eucanaã Ferraz, ao abordar sua obra, caracteriza a linguagem remetendo ao que, a meu ver, são os dois pilares de sua poética, o classicismo e a modernidade: "Expressão clássica, porém decididamente moderna" 
(FERRAZ, 2018, p. 17). ${ }^{4}$ Exemplo dessa combinação entre o simples e o complexo, entre o aparente e as entrelinhas, pode se entrever no livro escolhido, Coral, uma vez que ele apresenta

poemas marcados por contenção e brevidade, e o exemplo mais acabado talvez seja a joia que dá nome ao livro: "Ia e vinha / E a cada coisa perguntava / Que nome tinha". ${ }^{5}$ A alusão à paisagem marinha surge no título - "Coral" - e nos verbos do primeiro verso, que trazem o ritmo ondeante das marés em permanente movimento. Mas a ação central da cena - "perguntava" - lança a natureza para além do quadro natural e sugere um contato inaugural com o mundo. [...] Esse desvelamento do universo surge numa relação de escuta e fala, e assim o título sugere também um concerto de vozes - a que pergunta e as que, hipoteticamente, lhe respondem - formando um coral, entendido agora como canto em coro (FERRAZ, 2018, p. 20).

Tal análise deixa evidente a presença de diferentes camadas de sentido, apesar da simplicidade. Esta se relaciona à construção de imagens inesperadas e desconcertantes e a certo rompimento de expectativas - como em "Desligo da minha alma a melodia / Que inventei no ar. Tomo das imagens / Como um pássaro morto das folhagens / Tombando se desfaz na terra fria" (ANDRESEN, 1950, p. 15) -, pois, quando esperamos a transparência (do mar, do céu), Sophia apresenta-nos um mundo áspero e sombrio (FERRAZ, 2018), marcado, por exemplo, entre outros elementos, pela menção à morte, tema frequente, como nos simples versos de "Gráfico": "A mulher branca que a noite traz no ventre / Veio à tona das águas e morreu" (ANDRESEN, 1950, p. 24) ou no sutil "Ouve a fonte translúcida da quinta / Cercada de varandas onde a ausência / De alguém eterna mora e se debruça" (ANDRESEN, 1950, p. 41). Em função dessa combinação de opostos, é recorrente o uso associado de imagens hídricas e terrestres, luz e sombra, a claridade da aurora e a escuridão da noite. Essa associação pode ser pensada em ligação com um projeto maior:

\footnotetext{
${ }^{4}$ A tradição clássica está presente de diversas formas na poesia de Sophia de Mello Breyner Andresen, desde a estrutura de alguns poemas, o uso de recursos poéticos e a abordagem de temáticas e elementos da mitologia clássica. Por julgar que ele exige uma atenção em especial, não irei me dedicar a esse aspecto em especifico.

${ }^{5}$ ANDRESEN, 1950, p. 47.
} 
Sua consciência crítica vigilante, decididamente moderna, nunca desviou das ruínas do mundo. Mas se ameaças, morte e caos irrompem como a face terrível das coisas, o poema lhes devolve a perspectiva de fundação de uma vida pacificada e justa. Tratase de uma dimensão política, ética, moral, que cada novo livro confirmará e tornará mais intensa (FERRAZ, 2018, p. 19).

A dimensão política de que trata Ferraz pode ser entrevista principalmente nos poemas marcados pelo engajamento político, tornando característica da poética de Andresen a tensão entre uma aparente atemporalidade e a história e o presente circunstancial. Esse interesse pelo contexto político, apesar de não ser um aspecto em que irei me deter, deve ser ressaltado como uma marca da literatura portuguesa contemporânea (principalmente se pensarmos da metade do século XX até hoje), pois diversos autores - Sophia incluso - viveram a ditadura salazarista em Portugal e presenciaram seu encerramento com a Revolução dos Cravos em 24 de abril de 1975. Andresen teve, inclusive, papel ativo no movimento antiditatorial.

A solidão, outro elemento recorrente em seus poemas, lembra uma das observações de Staiger sobre o gênero lírico: "a poesia lírica manifesta-se como arte da solidão, que em estado puro é receptada apenas por pessoas que interiorizam essa solidão" (STAIGER, 1975, p. 49). No caso da modernidade e da obra da poeta portuguesa, essa solidão está ligada ao isolamento do sujeito consequente do contexto, da evolução da tecnologia que impregna as grandes cidades.

Terror de te amar num sítio tão frágil como o mundo.

Mal de te amar neste lugar de imperfeição

Onde tudo nos quebra e emudece

Onde tudo nos mente e nos separa (ANDRESEN, 1950, p. 29).

Ferraz (2018), aliás, retoma Eduardo Prado Coelho para afirmar que a poesia de Sophia tem dois "grandes inimigos": o tempo - "Esse tocar ausente e inseguro" (ANDRESEN, 1950, p. 38) e a cidade. Assim, em seus poemas, "Permanece o mundo natural como presença absoluta, inteireza oposta à fragmentação e à destinação trágica vividas pela humanidade desde que exilada daquela mesma natureza" (FERRAZ, 2018, p.19). 
Essa divisão pode, entretanto, ser anulada: através da linguagem - e, por isso, a poesia de Andresen é tão moderna, a meu ver. Segundo Ferraz, há em sua escrita uma "quebra da hierarquia entre o humano e o natural, e com isso a busca por uma indiferenciação entre natureza e palavra" (FERRAZ, 2018, p. 21). ${ }^{6}$ A unificação é alcançada através da transfiguração, através da linguagem, da realidade concreta, processo importante em sua poética; para tanto, conforme Morna (2005), a poeta recorre ao uso de símbolos marinhos e aéreos para exprimir a vivência trágica da existência e do convívio humano com a natureza. A autora também destaca o corpo como elemento importante desse processo, pois nele coabitam os elementos dessa convivência entre o humano e o natural. O corpo, na poesia de Andresen, é, assim, o corpo humano e o corpo da natureza.

Exemplar disso é "Mulheres à beira mar", em que o sujeito lírico está em comunhão com a natureza, e essa relação está toda representada pelo contato dos elementos naturais com partes do corpo. Os verbos no presente tornam a reprodução da disposição anímica mais acessível, de forma que é quase possível reproduzir, no momento da leitura, as sensações em nós, provocando o "momento eterno" de que falava Staiger (1975):

Confundindo os seus cabelos com os cabelos do vento, têm o corpo feliz de ser tão seu e tão denso em plena liberdade.

Lançam os braços pela praia fora e a brancura dos seus pulsos penetra nas espumas.

Passam aves de asas agudas e a curva dos seus olhos prolonga o interminável rastro no céu branco.

Com a boca colada ao horizonte aspiram longamente a virgindade de um mundo que nasceu.

O extremo dos seus dedos toca o cimo de delícia e vertigem onde o ar acaba e começa.

E aos seus ombros cola-se uma alga, feliz de ser tão verde (ANDRESEN, 1950, p. 21).

\footnotetext{
${ }^{6}$ A natureza, aliás, é um importante elemento da relação do sujeito com o mundo, em oposição ao ambiente urbano: "a permuta de espaços equivale à troca do pleno pelo vazio, da claridade pela escuridão, da paz pelo tumulto, da ordem pelo caos. Se o mar é uno e o eterno presentificados, a cidade é o lugar da divisão" (FERRAZ, 2018, p. 23).
} 
Essa relação entre o humano e o natural lembra a observação de Staiger (1975, p. 58) de que "Se a poesia lírica não é objetiva, não tem por isso que ser subjetiva. Se ela não representa o mundo exterior também não representa contudo o interior. O que se da é que 'interno' e 'externo', 'subjetivo' e 'objetivo' não estão absolutamente diversificados em poesia lírica". Na obra da portuguesa, interior e exterior estão com conjunção, o mundo objetivo e a subjetividade estão em constante associação, o que contribui para um tom impessoal.

A fusão entre ambos se dá, enfim, sempre por meio da linguagem. Ferraz (2018) corrobora essa ideia ao mencionar a defesa de Eduardo Prado Coelho de que a poeta é definida por "lógica e lírica". ${ }^{7}$ O brasileiro, aliás, procura reforçar essa ideia ao longo de todo seu texto crítico, pois explica a lírica andreseniana a partir de expressões de caráter formal, como "precisão da geometria" - relação tematizada, inclusive, pela própria poeta em "Poema de geometria e de silêncio / Ângulos agudos e lisos / Entre duas linhas vive o branco" (ANDRESEN, 1950, p. 89) - e "melodia sinuosa", sempre ressaltando o uso da palavra concreta, nítida, luminosa (FERRAZ, 2018). Brevidade, dicção límpida, imagens arrojadas, justaposição de palavras ou sintagmas e andamento rítmico que parece levar consigo o próprio sentido dos versos, sílaba a sílaba, são outros traços que estão sempre em debate em seu texto.

$\mathrm{O}$ trabalho consciente de uso de sílabas significantes é um aspecto a que se dedica Rosa Maria Martelo (2005). A autora defende que, semelhantemente a Mallarmé, "quase apetece dizer que Sophia sempre entendeu que a sua poesia não se faria nem com ideias nem com palavras, mas sim com sílabas, e que o seu conceito de justeza da linguagem poética radica precisamente nesta perspectiva" (MARTELO, 2005, p. 60). Utilizando uma imagem que remete ao clássico - tão caro à sua poesia -, é como se Sophia fosse uma Ariadne-poeta (MARTELO, 2005) que, com o fio de silabas, traçasse o caminho no labirinto do Minotauro que é um poema.

A autora também ressalta a poesia como elemento que liga um tempo primordial, mítico, natural e o ser. Todavia, em sua perspectiva, "essa busca não implica ignorar a existência de uma fractura entre os nomes e as coisas, ou entre os sons e os sentidos" (MARTELO, 2005, p 67). O que Sophia faz é reconhecer "ser sobre a própria fractura inerente à possibilidade de significação que a poesia lança um fio de silabas, máxima

${ }^{7}$ Entendo, aqui, lógica como preocupação formal. 
expressão do humano desejo de "inseparação absoluta"' (MARTELO, 2005, p. 67). Sua poesia seria, assim, por causa da transcendência, uma poesia de religação.

Exemplares não só do trabalho com a potencialidade sonora dos termos, mas da atenção à silaba são os dois poemas a seguir, em que um mesmo recurso se faz presente, a repetição de "Chamei" para explorar justamente sua primeira sílaba, "ch”, que, em repetição, lembra o som do mar - elemento presente em ambos os textos:

Eu chamei-te para ser a torre

Que viste um dia branca ao pé do mar,

Chamei-te para me perder nos teus caminhos,

Chamei-te para sonhar o que sonhaste.

Chamei-te para não ser eu:

Pedi-te que apagasses

A torre que eu fui, os meus caminhos, os sonhos que sonhei (ANDRESEN, 1950, p. 11)

Chamei por mim quando cantava o mar

Chamei por mim quando corriam fontes

Chamei por mim quando os heróis morriam

E cada ser me deu sinal de mim (ANDRESEN, 1950, p. 13).

Feitos tais apontamos sobre a poesia da portuguesa Sophia de Mello Breyner Andresen, pode-se tomar como chave de leitura dos seus poemas desvinculados a uma luta política a lírica como poesia da solidão compartilhada apenas pelos que reproduzem a disposição anímica. Afirmo tal pensando que seus poemas parecem servir à repercussão íntima no leitor, ao afloramento de sensações que independem de contexto - e é isso, talvez, que dá tanto poder aos seus textos. No recorte aqui realizado, a desumanização/despersonalização ressaltada por Friedrich em relação à lírica moderna é extrema (mas de forma distinta de Mallarmé), pois lida com sentimentos quase universais. Essa universalidade pode ser motivada por poemas autônomos, com sentido encerrado em si, que apresentam um cuidado com a linguagem e um rigor formal típico dos poetas modernos. Tem-se, assim, a formação de uma realidade, não a mera reprodução do mundo.

O contexto, porém, ainda se faz entrever na desautomatização que se pode apontar em tais poemas. $\mathrm{O}$ sujeito lírico parece desligar-se, 
abandonar o mundo pós-industrial, a cidade e seu ritmo frenético, para se entregar à natureza, às sensações por ela provocadas. Esse contato com o natural exprime-se em uma poesia que fica entre o derramamento lírico das concepções mais clássicas (e que é evidente no uso da sinestesia) e o controle de emoções simbolistas da lírica moderna (expresso principalmente na linguagem simples). Isso se dá pela associação, por ela defendida, entre a experiência e sua transformação em material poético:

Todo o poeta, todo o artista é artesão duma linguagem. Mas o artesanato das artes poéticas não nasce de si mesmo, isto é da relação com uma matéria, como nas artes artesanais. $\mathrm{O}$ artesanato das artes poéticas nasce da própria poesia à qual está consubstancialmente unido. Se um poeta diz «obscuro», «amplo», «branco», «pedra», é porque estas palavras nomeiam a sua visão do mundo, a sua ligação com as coisas. Não foram palavras escolhidas esteticamente pela sua beleza, foram escolhidas pela sua realidade, pela sua necessidade, pelo seu poder poético de estabelecer uma aliança. E é da obstinação sem tréguas que a poesia exige que nasce $\mathrm{o}$ «obstinado rigor» do poema. $\mathrm{O}$ verso é denso, tenso como um arco, exactamente dito, porque os dias foram densos, tensos como arcos, exactamente vividos. $\mathrm{O}$ equilíbrio das palavras entre si é o equilíbrio dos momentos entre si (ANDRESEN, [1968], p. 221).

O tempo dividido da obra de Andresen é, enfim, o tempo do sujeito dividido da modernidade. Na transfiguração de sua poesia, porém, ele encontra alguma redenção.

\section{Referências}

ANDRESEN, Sophia de Mello Breyner. Coral. Porto: Livraria Simões Lopes, 1950.

ANDRESEN, Sophia de Mello Breyner. Arte poética II. In: Antologia: 1944-1967. Lisboa: Portugália, [1968]. (Colecção Poetas de Hoje, 28). p. 220-221.

BERARDINELLI, Alfonso. As muitas vozes da poesia moderna. In: . Da poesia à prosa. Org. e prefácio Maria Betânia Amoroso. Trad. Maurício Santana Dias. São Paulo: Cosac Naify, 2007. p. 17-41. 
FERRAZ, Eucanaã. Apresentação: breve percurso rente ao mar. In: ANDRESEN, Sophia de Mello Breyner. Coral e outros poemas. São Paulo: Companhia das Letras, 2018. p.17-42.

FEIDELSON JR., Charles. Symbolism and american literature. 7. ed. Chicago: University of Chicago Press, 1969. p. 56.

FRIEDRICH, Hugo. Estrutura da lírica moderna: da metade do século XIX a meados do século XX. Tradução de Marise M. Curioni; Dora F. da Silva. São Paulo: Duas Cidades, 1978. p. 9-139.

GOMES, Álvaro Cardoso. A estética simbolista. São Paulo: Cultrix, 1985. p. 9-29.

LOURENÇO, Eduardo. Prefácio. In: ANDRESEN, Sophia de Mello Breyner. Antologia. 4. ed. com. Lisboa: Moraes Editores, 1975. p. I-VII.

MARTELO, Rosa Maria. Sophia e o fio de sílabas. In: Conselho Directivo da FLUP; Conselho Científico da FLUP (Org.). Estudos em homenagem a Sophia de Mello Breyner Andresen. Porto: Faculdade de Letras da Universidade do Porto, 2005. Disponível em: $<$ http://ler.letras.up.pt/ uploads/ficheiros/1160.pdf $>$. Acesso em: 22 jun. 2018.

MORNA, Fátima Freitas. Senhores que podem morrer: (meditação acerca de um poema de Sophia de Mello Breyner Andresen). In: Conselho Directivo da FLUP; Conselho Científico da FLUP (Org.). Estudos em homenagem a Sophia de Mello Breyner Andresen. Porto: Faculdade de Letras da Universidade do Porto, 2005. Disponível em: $<$ http://ler.letras. up.pt/uploads/ficheiros/1162.pdf $>$. Acesso em: 22 jun. 2018.

ROSENFELD, Anatol. O teatro épico. São Paulo: Perspectiva, 1985. (Coleção Debates). p. 15-26.

STAIGER, Emil. Estilo lírico: a recordação. In: . Conceitos fundamentais da poética. Tradução de Celeste Aida Galeão. Rio de Janeiro: Tempo Brasileiro, 1975. (Biblioteca Tempo Universitário, 16). p. 19-75. 